\title{
Effect of Headgear and Class II Traction on Upper Airway Dimensions and Hyoid Bone Position in Non-Extraction Patients with Class II Division 1 Malocclusion
}

\author{
Bowen Zheng, Zixi Jiang, Fan Liu, Na An, Ying Zheng, Yang Zhang and Yi Liu
}

\author{
Department of Orthodontics, School of Stomatology, China Medical University, Shenyang, China
}

(Accepted for publication, October 21, 2014)

\begin{abstract}
Our aim was to analyze the effect of headgear on upper airway dimension and hyoid bone position on non-extraction patients with Class II division 1 malocclusion. Ninety patients with Class II division 1 malocclusion were included and divided into three groups (Group A: treated with headgears and Class II traction; Group B: performed with Class II traction; and Group C: no treatment). The lateral projection was measured at the beginning and end of treatment. Cephalometric analyses of the dentofacial structure, upper airway dimension and hyoid bone position were performed before and after treatment. The data were analyzed by paired t-test and independent sample t-test. SNA significantly decreased in Group A after treatment $(\mathrm{P}<0.01)$, and SNB, ANB and Wits significantly changed in Group A and Group B. L1-MP, L1-NB and Z angle significantly increased, while overjet, overbite and lower lip measurements significantly decreased in Group A and Group B. In upper airway measurements, V-LPW, PNS-V, PNS-U and T-V significantly increased for three groups. Moreover, the hyoid bone position had a change in Group A and Group B. The upper airway dimensions were not decreased by headgear treatment or Class II traction in patients with Class II division 1 malocclusion. Class II traction treatment affected the position of the hyoid bone.
\end{abstract}

Key words: Headgear, Class II malocclusion, Airway dimension, Non-extraction treatment

\section{Introduction}

Class II division 1 malocclusion is one of the most common malocclusions in clinic. Due to the obvious deformity, it affected facial appearance and masticatory function. As a result, the desire of treatment was urgent.

Distal displacement of the maxillary molars and decrease of overjet and overbite have been an integral part of orthodontic treatment for patients with Class II division 1 malocclusions. Due to possible side-effects of premolar extraction, non-extraction treatment became increasingly common in the $1970 \mathrm{~s}^{1)}$. More and more orthodontists used appliances to improve facial esthetics that don't have serious crowding and protrusion. Some clinicians are dedicated to using extraoral traction ${ }^{2,3}$, whereas others, because of problems related to compliance, prefer intermaxillary or intramaxillary appliances.

Different appliance has its advantages and indications. The effect on cervical headgear on craniofacial growth, and the inhibition of maxillary growth has been commonly described as

Correspondence to: Dr. Yi Liu, Department of Orthodontics, School of Stomatology, China Medical University, Nanjing North Street 117\#, He Ping District Shenyang 110002, China; Tel: +86 24 31973999; Fax: +86 24 31973999; E-mail: liuyi256@126.com an important treatment. Lima showed that headgear appliances followed by fixed orthodontic treatment played an important role in dentoskeletal changes in Class II division 1 malocclusion $^{4}$. Fixed appliance combined with cervical headgear is the optional method for treatment of Class II division 1 malocclusion.

Some studies have suggested that Class II malocclusion is associated with upper airway narrowing ${ }^{5,6)}$. If effective treatments performed, the upper airway dimension would increase. Sahoo Nk showed an overall increase in airway dimension and improvement in hyoid position in patients with skeletal Class II malocclusion treated by combined orthodontics and bilateral sagittal split ramus osteotomy ${ }^{7}$. However, Forsus Fatigue Resistant Device appliance are considered to produce dentoalveolar changes but do not cause any significant posterior airway changes ${ }^{8}$. Shigetoshi reported that a significant reduction in the middle upper airway dimension was demonstrated by the wearing of cervical headgear during sleep ${ }^{9}$. The findings about whether the headgears followed by fixed orthodontic treatment have the effect on the upper airway were rarely reported.

The purpose of this study was to evaluate the changes of sagittal diameter of upper airway and hyoid position of patients 


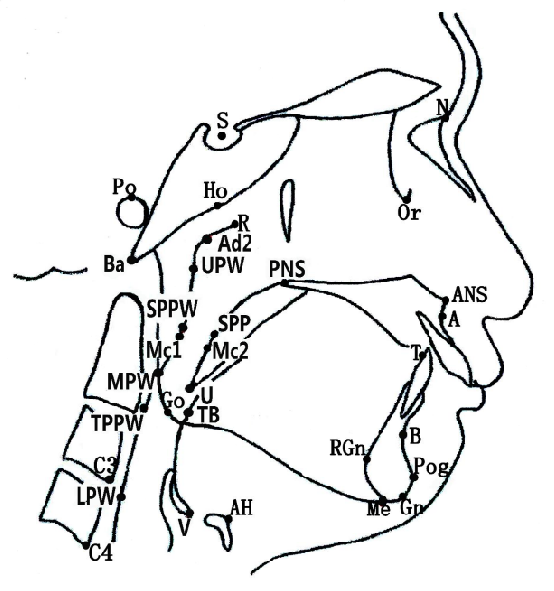

Figure 1. Landmarks. S, Sella; N, Nasion; Po, Porion; Ba, Basion; Ho, Hormion; Or, Orbitale; ANS, Anterior nasal spine; PNS, Posterior nasal spine; A, the deepest point on the anterior contour of the maxillary; B, the deepest point on the anterior contour of the mandibular aleveolar projection; Go, Gonion; Pog, the most anterior part of the bony chin; Me, Menton; Gn, Gnathion; RGn, the most posterior point on mandibular symphysis; R, the intersection point of posterior pharyngeal wall and the line from PNS to Ho; Ad2, the intersection point of posterior pharyngeal wall and the line from the vertical counterpoint from PNS to the line from $\mathrm{S}$ to $\mathrm{Ba}$; UPW, the intersection point of posterior pharyngeal wall and the line from PNS to Ba; MPW, horizontal counterpoint from tip of soft palate on posterior pharyngeal wall; LPW, horizontal counterpoint from base of epiglottis on posterior pharyngeal wall; $\mathrm{U}$, tip of soft palate; $\mathrm{V}$, base of epiglottis; SPP, the intersection point of soft palate and the horizontal line from the midpoint of the line from PNS to $\mathrm{U}$ to the line from Go to B; SPPW, the intersection point of posterior pharyngeal wall and the horizontal line from the midpoint of the line from PNS to $U$ to the line from Go to $\mathrm{B}$; TB, the intersection point of root of tongue and the line from Go to B; TPPW, the intersection point of posterior pharyngeal wall and the extended line of the line from Go to B; AH, Anteriosuperior hyoidale; C3, Anterioinferior limit of third cervical vertebra; $\mathrm{C} 4$, Anterioinferior limit of fourth cervical vertebra; T, Tougue tip; Mc1, The point on posterior pharyngeal wall where the postpalatal airway is narrowest; $\mathrm{Mc2}$, The point on soft palate where the postpalatal airway is narrowest

with Class II division 1 malocclusion after the treatment with headgears and Class II traction.

\section{Materials and Methods}

Ethics approval for the study was obtained from the China Medical University Ethics Committee. The study consisted of 90 patients (42 men and 48 women) with Class II division 1 malocclusion, the mean age was 11.9 (range: 11-14) years. They were selected from the Department of Orthodontics, Hospital of Stomatology, China Medical University. Inclusion criteria were: 1. Clinical examination and cephalometric analysis showed the subjects were all Class II division 1 malocclusion with the mild or moderate hypogenesis of mandibular, which were not the indication of surgery;
2. The molar relationship was distal molar relationship;

3. The patient compliance was favorable and ensured that wearing the maxillary protraction reached more than 14 hours per day;

4. No systematic diseases;

5. No history of temporomandibular disorders;

6. No history of orthodontic treatment;

They were divided into three groups, Group A was treated with headgears and Class II traction, the overjet was 5-8mm, maxillary dentoalveolar and anterior teeth protrusion; Group B was performed with Class II traction, the overjet was 3-5mm, slight protrusion of maxillary dentoalveolar and anterior teeth; Group C was no treatment.

\section{Treatment methods}

All cases were performed by non-extraction orthodontic treatment. The fixed appliances with headgear combined Class II elastic traction were performed in Group A and the fixed appliances with Class II traction were performed in Group B. The average treatment time was 19.2 months. No treatment cases were performed in Group C. The average observation time of Group C was 17.8 months.

The force level exerted by headgear was $300-350 \mathrm{~g}^{10)}$. The average time was more than 14 hours per day ${ }^{11)}$, and the average of total headgear treatment time was 3.5 months. Traction direction should depend on vertical facial types.

\section{Measurement methods}

The lateral cephalograms were taken in a natural head posture before and after treatment. Make sure that the upper and lower lips were relaxed; Frankfort horizontal plane paralleled to the floor and the mandible was in the intercuspal position, with no swallowing. Take the left and right lateral photographic superimposition as the standard.

\section{The control of method error}

Cephalometric radiographs were analyzed by the Winceph 8.0 software. The lateral cephalograms were measured by the same investigator. A month later, the measurement was carried out again by the same examer. Casual and systematic errors were calculated by comparing the first and second measurements and one-way Analysis of variance (ANOVA) demonstrated there was no significant difference.

Cephalometric and anatomic landmarks are shown in Fig. 1. The 41 measurements ${ }^{2,5,19,20-24)}$ of cephalometric radiographs are as follows:

1. Skeletal measurements: SNA (the angle sella to nasion to subspinale), SNB (the angle sella to nasion to supramentale), ANB (the angle subspinale to nasion to supramentale), GoGn-SN (the intersection point of mandibular plane (Go-Gn) and the SN line, the inclination of mandibular plane), Wits (the distance between 
Bowen Zheng Effect of Hadgear and Cass II Traction

Table 1. Comparison of the Skeletal, Dental and Soft Tissue Measurements before and after Treatment (Mean \pm SD)

\begin{tabular}{|c|c|c|c|c|c|c|c|c|c|}
\hline \multirow[t]{2}{*}{ Measurement } & \multicolumn{3}{|c|}{ Group A } & \multicolumn{3}{|c|}{ Group B } & \multicolumn{3}{|c|}{ Group C } \\
\hline & Pretreatment & posttreatment & $\mathrm{P}$ & pretreatment & posttreatment & $\mathrm{P}$ & before & after & $\mathrm{P}$ \\
\hline $\operatorname{SNA}\left({ }^{\circ}\right)$ & $81.46 \pm 3.32$ & $80.30 \pm 3.64$ & $* *$ & $82.30 \pm 4.16$ & $81.82 \pm 4.23$ & NS & $81.59 \pm 1.23$ & $82.01 \pm 2.21$ & NS \\
\hline $\operatorname{SNB}\left({ }^{\circ}\right)$ & $76.85 \pm 3.40$ & $77.63 \pm 3.74$ & $* *$ & $76.67 \pm 2.36$ & $77.70 \pm 2.39$ & $* *$ & $77.90 \pm 3.34$ & $78.45 \pm 2.95$ & NS \\
\hline $\operatorname{ANB}\left({ }^{\circ}\right)$ & $4.62 \pm 1.53$ & $3.52 \pm 1.20$ & $* *$ & $4.87 \pm 1.39$ & $3.35 \pm 1.08$ & $* *$ & $3.85 \pm 0.98$ & $4.01 \pm 1.52$ & NS \\
\hline GoGn-SN( $\left(^{\circ}\right)$ & $34.15 \pm 5.38$ & $34.07 \pm 5.36$ & NS & $33.01 \pm 5.18$ & $33.36 \pm 5.56$ & NS & $33.97 \pm 4.89$ & $34.03 \pm 4.37$ & NS \\
\hline Wits(mm) & $0.99 \pm 2.73$ & $-0.60 \pm 1.87$ & $* *$ & $0.66 \pm 2.64$ & $-0.81 \pm 1.64$ & $* *$ & $0.86 \pm 1.99$ & $0.89 \pm 2.13$ & NS \\
\hline Ul-SN( $\left(^{\circ}\right)$ & $110.32 \pm 4.80$ & $108.63 \pm 4.69$ & $* *$ & $108.24 \pm 7.09$ & $106.10 \pm 5.63$ & NS & $110.56 \pm .68$ & $112.21 \pm 4.96$ & $*$ \\
\hline $\mathrm{U} 1-\mathrm{NA}\left({ }^{\circ}\right)$ & $27.82 \pm 3.43$ & $26.40 \pm 3.43$ & $*$ & $25.93 \pm 7.04$ & $24.28 \pm 6.30$ & NS & $26.04 \pm 4.55$ & $26.18 \pm 5.11$ & $*$ \\
\hline $\mathrm{L} 1-\mathrm{MP}\left({ }^{\circ}\right)$ & $94.79 \pm 6.56$ & $97.27 \pm 5.22$ & $* *$ & $93.75 \pm 5.63$ & $96.18 \pm 5.31$ & $* *$ & $93.99 \pm 5.41$ & $94.08 \pm 5.66$ & NS \\
\hline $\mathrm{L} 1-\mathrm{NB}\left({ }^{\circ}\right)$ & $25.74 \pm 4.27$ & $31.55 \pm 5.10$ & $* *$ & $25.29 \pm 3.22$ & $28.84 \pm 2.92$ & $* *$ & $25.88 \pm 2.78$ & $26.06 \pm 3.11$ & NS \\
\hline $\mathrm{U} 1$ to $\mathrm{L} 1\left(^{\circ}\right)$ & $122.88 \pm 8.57$ & $120.09 \pm 5.97$ & NS & $125.42 \pm 7.94$ & $123.99 \pm 5.78$ & NS & $122.94 \pm 6.13$ & $120.78 \pm 5.99$ & $*$ \\
\hline Overjet(mm) & $5.51 \pm 2.26$ & $2.15 \pm 1.19$ & $* *$ & $4.75 \pm 2.24$ & $2.88 \pm 1.03$ & $* *$ & $4.98 \pm 2.07$ & $4.04 \pm 1.88$ & NS \\
\hline Overbite(mm) & $2.99 \pm 1.20$ & $1.77 \pm 0.72$ & $* *$ & $3.18 \pm 1.28$ & $2.20 \pm 0.70$ & $* *$ & $3.04 \pm 0.94$ & $3.25 \pm 1.01$ & NS \\
\hline Upper lip(mm) & $-0.36 \pm 1.91$ & $0.69 \pm 1.08$ & $* *$ & $0.04 \pm 2.06$ & $-0.70 \pm 1.66$ & $* *$ & $0.16 \pm 1.99$ & $0.08 \pm 2.04$ & NS \\
\hline Lower lip(mm) & $2.75 \pm 2.57$ & $2.23 \pm 1.81$ & $*$ & $2.11 \pm 1.29$ & $1.55 \pm 1.37$ & $* *$ & $2.01 \pm 0.16$ & $2.11 \pm 0.99$ & NS \\
\hline $\mathrm{Z}$ angle $\left({ }^{\circ}\right)$ & $72.35 \pm 5.27$ & $73.93 \pm 4.14$ & $*$ & $70.00 \pm 4.49$ & $71.21 \pm 4.59$ & $* *$ & $72.11 \pm 4.99$ & $71.69 \pm 4.17$ & NS \\
\hline
\end{tabular}

NS indicates statistical nonsignificance; * $\mathrm{P}<0.05 ; * * \mathrm{P}<0.01$

the vertical counterpoint from A to Occlusal plane and the vertical counterpoint from B to Occlusal plane)

2. Dentoalveolar measurements: U1-NA(angle formed by the maxillary incisor's long axis and the NA line, the maxillary incisor inclination), U1-SN(angle formed by the maxillary incisor's long axis and the $\mathrm{SN}$ line, the maxillary incisor inclination relative to anterior cranial base), LI-NB(angle formed by the mandibular incisor's long axis and the NB line, the mandibular incisor inclination), L1-MP (angle formed by the mandibular incisor's long axis and the MP line, the mandibular incisor inclination relative to mandibular plane), U1-LI (angle formed by the maxillary incisor's long axis and mandibular incisor's long axis), Overjet, Overbite

3. Soft tissue measurements: Lower lip (the distance from anterior point of lower lip to the extending line between the nose tip and soft tissue pogonion), Upper lip (the distance from anterior point of upper lip to the extending line between the nose tip and soft tissue pogonion), $\mathrm{Z}$ angle (the interior angle of the line from soft tissue pogonion to the forefront lip (upper lip or lower lip) and the FH line)

4.Upper airway and hyoid measurements: Upper airway measurements: PNS-R, the distance between PNS and R; PNS$\mathrm{Ba}$, total lower sagittal depth of the bony nasopharynx; PNS-UPW, width of Nasopharynx; SPP-SPPW, the distance between SPP and SPPW; U-MPW, the width of airway behind tip of soft palate; Mcl-Mc2, minimum distance between the soft palate and the posterior pharynx wall; TB-TPPW, Posterior airway space of root of tongue, the distance of intersection point (TB, TPPW) of posterior pharyngeal wall and the line from Go to B; V-LPW, the distance between V and LPW; C3-RGn, the distance between C3 and RGn; PNS-V, airway length (PNS-V); PNS-U, Soft palate length (PNS-P); T-V, Tongue length. Hyoid measurements: The vertical measurements: $\mathrm{AH}-\mathrm{SN}$, the distance between $\mathrm{AH}$ and the vertical counterpoint from $\mathrm{AH}$ to the $\mathrm{SN}$ line; $\mathrm{AH}-\mathrm{FH}$, the distance between $\mathrm{AH}$ and the vertical counterpoint from $\mathrm{AH}$ to the $\mathrm{FH}$ plane(FH plane, line through Or and Po); AH-PP, the distance between $\mathrm{AH}$ and the vertical counterpoint from $\mathrm{AH}$ to the PP plane (palatal plane, the line connecting ANS and PNS); AH-OP, the distance between $\mathrm{AH}$ and the vertical counterpoint from $\mathrm{AH}$ to the occlusal plane; AH-MP, the distance between AH and the vertical counterpoint from AH to the MP plane (mandibular plane, the line connecting $\mathrm{Gn}$ and Go); AH-PNS, the distance between $\mathrm{AH}$ and PNS; AH-Y, the distance between $\mathrm{AH}$ and the vertical counterpoint from $\mathrm{AH}$ to $\mathrm{Y}$ axis (the line from $\mathrm{S}$ to $\mathrm{Gn}$ ). The horizontal measurements: AH-Or, the distance between Or and the vertical counterpoint from $\mathrm{AH}$ to the $\mathrm{FH}$ plane; $\mathrm{AH}-\mathrm{C} 3$, the distance between $\mathrm{AH}$ and $\mathrm{C} 3$; $\mathrm{AH}-\mathrm{RG}$, the distance between $\mathrm{AH}$ and RGn; $\mathrm{AH}-\mathrm{Me}$, the distance between $\mathrm{AH}$ and $\mathrm{Me}$; $\mathrm{AH}-\mathrm{NPog}$, the distance between $\mathrm{AH}$ and the line from $\mathrm{N}$ to Pog; $\mathrm{C} 3-\mathrm{Me}$, the distance between $\mathrm{C} 3$ and $\mathrm{Me}$; $\mathrm{AH}-\mathrm{CVP}$, the distance between $\mathrm{AH}$ and the vertical counterpoint from $\mathrm{AH}$ to the line from $\mathrm{C} 3$ to $\mathrm{C} 4$.

\section{Statistical Analysis}

The statistical analyses were calculated using SPSS17.0 (SPSS Inc, Chicago). Chi-square tests were used to check the sex distribution, and independent-samples t-test was used to compare the age differences between groups. Paired t-tests were used to compare the pretreatment and posttreatment measurements. 
Independent-samples t-test was used to compare the differences between groups in pretreatment and posttreatment measurements. $\mathrm{P}<0.05$ was considered statistically significant.

\section{Results}

\section{Sex and age distribution}

There was no significant difference in sex distribution among Group A (13 men, 17 women), Group B (15 men, 15 women) and Group C (14 men, 16 women) by Chi-square test $(\mathrm{P}>0.05)$.

The average age of Group A was $11.96 \pm 1.16$ years. The average age of Group B was 11.91 \pm 1.25 years. The average age of Group $\mathrm{C}$ was $11.89 \pm 1.21$ years. There was no significant difference in age composition among groups by independent-samples t-test $(\mathrm{P}>0.05)$

\section{The results of skeletal, dentoalveolar and soft tissue variance (Table 1)}

In group A, maxillary growth was inhibited, SNA decreased significantly $(\mathrm{P}<0.01)$, mandibular sagittal variation was significantly promoted. SNA had no significant change in Group B. ANB and Wits decreased $(\mathrm{P}<0.01)$, and $\mathrm{SNB}(\mathrm{P}<0.01)$ increased in both groups.

The overjet and overbite decreased, L1-MP, L1-NB increased and mandible incisor labial inclined in each group after treatment $(\mathrm{P}<0.01)$. There was no significant difference in U1-L1 angle in the two groups. In Group A, maxillary incisors were retracted, U1-SN angle and U1-NA angle decreased significantly $(\mathrm{P}<0.01)$. There was, however, no difference in U1-SN angle and U1-NA angle in Group B.

Lower lip decreased, $\mathrm{Z}$ angle increased significantly in each group $(\mathrm{P}<0.05)$. Upper lip increased in Group A $(\mathrm{P}<0.01)$; however, decreased in Group B $(\mathrm{P}<0.01)$.

In group $\mathrm{C}, \mathrm{U} 1-\mathrm{NA}$ and $\mathrm{U} 1-\mathrm{SN}$ increased $(\mathrm{P}<0.05)$; and $\mathrm{U} 1-$ L1 decreased $(\mathrm{P}<0.05)$.

\section{The results of upper airway and position of hyoid bone variation (Table 2)}

In the upper airway variation, V-LP W, PNS-V, PNS-U significantly increased in the three groups. T-V significantly increased in Group A and B, no significant difference in Group C.

In the vertical position of hyoid variation, $\mathrm{AH}-\mathrm{SN}, \mathrm{AH}-\mathrm{FH}$, AH-PP, AH-PNS significantly increased in Group A and B. The direction of hyoid growth had been changed to downward.

In the horizontal position of hyoid variation, $\mathrm{AH}-\mathrm{NPog}, \mathrm{AH}-$ CVP, C3-Me significantly increased in three groups. The direction of hyoid growth had been changed to forward. AH-C3 significantly increased in Group A; however, no significant difference in Group $\mathrm{B}$ and $\mathrm{C}$.

The comparison of changes before and after treatment between Group A and B showed that Overjet $(\mathrm{P}<0.05)$ and Upper lip
$(\mathrm{P}<0.01)$ changed significantly, no significant difference in Group C.

\section{Discussion}

This study reported the changes of upper airway dimension and hyoid bone position in non-extraction patients with Class II division 1 malocclusion, about 11 years old, using Class II traction with or without headgear treatment. Measurements of pretreatment and posttreatment in patients with headgears showed that maxillary growth was obviously inhibited, but mandible growth wasn't affected, which was consistent with previous studies ${ }^{12,13}$.

The overjet and overbite were improved, due to the maxillary molars distal displacement, the maxillary arch expansion, the maxillary inhibition, the mandible growth, the maxillary incisors palatal displacement and mandible incisors labial inclination.

Jacobson ${ }^{14)}$ believed that the ANB angle was not always an accurate method of establishing the actual amount of apical base divergence. The effect of angulation of jaws and occlusal plane on jaw relationship based on Nasion, the rotational effect and the anteroposterior positions of the jaws relative to the anterior cranial base were the factors leading to its inaccuracy. In order to determine the reliability of the ANB angle, the Wits appraisal was used to complementally show the anteroposterior relationship of jaws. In our study, the Wits significantly decreased in Group A and $\mathrm{B}$ after treatment, which showed the relative coordination of maxillary and mandible.

The SNB angle significantly increased in Group A and B, which is probably the Class II traction effect or other factors. Thomas ${ }^{15}$ ) reported that headgear treatment made the upper dental arch expansion and the overjet and overbite decrease, which could change original occlusion. It means that the growth of the mandible was no longer limited. Between Group A and B, there was no significant difference in SNB angle, which illustrated headgear had no evident effect on mandible growth, but Class II traction in this study.

In the dentoalveolar variation, the incisors inclination greatly improved in Group A, because of U1-SN and U1-NA decrease, after treatment with headgear. However, there was no significant difference in Group B. That's because headgear treatment could distally displace maxillary molars, increase molars anchorage and provide places for incisors retraction. In addition, U1-L1 wasn't change significantly in the patients of Group A and B, due to the maxillary incisors palatal inclination and mandible incisors labial inclination. In Group C, U1-SN and U1-NA increased, U1-L1 decreased. No restriction of patients with Class II division 1 malocclusion may aggravate incisors inclination and affect the mandibular development.

Recent years, more and more orthodontists ${ }^{16,17)}$ concerned on facial soft tissue profile of the patients, which didn't change with the dentition entirely. So analyses of orthodontic treatment on both hard and soft tissue were required. In this study, the profile 
Bowen Zheng Effect of Hadgear and Cass II Traction

Table 2. Comparison of the Upper Airway Demensions and the Hyoid Measurements before and after Treatment (Mean \pm SD)

\begin{tabular}{|c|c|c|c|c|c|c|c|c|c|}
\hline \multirow[t]{2}{*}{ Measurement } & \multicolumn{3}{|c|}{ Group A } & \multicolumn{3}{|c|}{ Group B } & \multicolumn{3}{|c|}{ Group C } \\
\hline & Pretreatment & Posttreatment & $\mathrm{P}$ & Pretreatment & Posttreatment & $\mathrm{P}$ & Pretreatment & Posttreatment & $\mathrm{P}$ \\
\hline \multicolumn{10}{|l|}{ Nasopharynx } \\
\hline PNS-R(mm) & $16.85 \pm 2.4 \mathrm{C}$ & $917.23 \pm 2.24$ & NS & $17.34 \pm 2.60$ & $18.05 \pm 2.41$ & NS & $17.67 \pm 2.22$ & $17.94 \pm 2.95$ & NS \\
\hline PNS-Ba(mm) & $42.19 \pm 3.33$ & $342.83 \pm 3.82$ & NS & $44.42 \pm 3.54$ & $45.23 \pm 4.11$ & NS & $43.65 \pm 3.01$ & $43.26 \pm 4.79$ & NS \\
\hline PNS-UPW(mm) & $21.70 \pm 3.75$ & $522.59 \pm 4.02$ & NS & $22.49 \pm 3.88$ & $23.37 \pm 3.42$ & NS & $21.99 \pm 3.12$ & $22.54 \pm 3.62$ & NS \\
\hline \multicolumn{10}{|l|}{ Oropharynx } \\
\hline SPP-SPPW $(\mathrm{mm})$ & $9.78 \pm 2.75$ & $10.18 \pm 2.19$ & NS & $10.76 \pm 2.27$ & $10.85 \pm 2.59$ & NS & $10.09 \pm 2.54$ & $10.93 \pm 2.17$ & NS \\
\hline $\mathrm{U}-\mathrm{MPW}(\mathrm{mm})$ & $8.81 \pm 2.36$ & $9.00 \pm 2.04$ & NS & $9.35 \pm 2.70$ & $9.61 \pm 2.50$ & NS & $8.65 \pm 2.47$ & $9.06 \pm 2.72$ & NS \\
\hline $\operatorname{Mcl}-\mathrm{Mc} 2(\mathrm{~mm})$ & $7.95 \pm 2.42$ & $8.27 \pm 2.10$ & NS & $8.68 \pm 2.43$ & $8.75 \pm 2.48$ & NS & $8.05 \pm 2.11$ & $8.17 \pm 2.34$ & NS \\
\hline TB-TPPW(mm) & $9.63 \pm 2.77$ & $9.83 \pm 2.88$ & NS & $10.74 \pm 3.21$ & $10.85 \pm 3.50$ & NS & $10.03 \pm 2.21$ & $10.16 \pm 2.61$ & NS \\
\hline \multicolumn{10}{|l|}{ Hypopharynx } \\
\hline V-LPW(mm) & $18.89 \pm 2.38$ & $20.20 \pm 2.99$ & $*$ & $19.52 \pm 2.49$ & $20.40 \pm 2.78$ & $*$ & $18.92 \pm 2.20$ & $19.90 \pm 2.39$ & $*$ \\
\hline C3-RGn(mm) & $61.93 \pm 5.19$ & $63.47 \pm 5.72$ & NS & $65.16 \pm 8.03$ & $66.19 \pm 8.37$ & NS & $62.30 \pm 5.93$ & $63.75 \pm 6.88$ & NS \\
\hline PNS-V(mm) & $56.57 \pm 3.97$ & $60.48 \pm 5.46$ & $* *$ & $58.64 \pm 5.77$ & $61.18 \pm 5.51$ & $* *$ & $57.14 \pm 5.11$ & $58.65 \pm 5.22$ & $*$ \\
\hline \multicolumn{10}{|l|}{ Soft palate } \\
\hline PNS-U(mm) & $30.03 \pm 2.32$ & $30.76 \pm 2.45$ & $*$ & $30.37 \pm 2.80$ & $31.14 \pm 2.73$ & $*$ & $30.17 \pm 2.48$ & $30.66 \pm 2.52$ & $*$ \\
\hline \multicolumn{10}{|l|}{ Tongue } \\
\hline $\mathrm{T}-\mathrm{V}(\mathrm{mm})$ & $62.44 \pm 4.58$ & $64.90 \pm 5.40$ & $* *$ & $64.83 \pm 5.81$ & $66.48 \pm 5.47$ & $*$ & $63.54 \pm 5.12$ & $63.58 \pm 5.27$ & NS \\
\hline \multicolumn{10}{|c|}{ The vertical measurements of tongue } \\
\hline $\mathrm{AH}-\mathrm{SN}(\mathrm{mm})$ & $96.56 \pm 6.73$ & $102.04 \pm 7.94$ & $* *$ & $101.52 \pm 8.88$ & $105.07 \pm 8.41$ & $* *$ & $100.38 \pm 4.55$ & $102.53 \pm 5.71$ & $*$ \\
\hline AH-FH(mm) & $75.22 \pm 5.27$ & $80.08 \pm 6.22$ & $* *$ & $77.84 \pm 7.37$ & $81.09 \pm 7.88$ & $* *$ & $76.74 \pm 6.55$ & $78.79 \pm 7.04$ & $*$ \\
\hline $\mathrm{AH}-\mathrm{PP}(\mathrm{mm})$ & $54.75 \pm 4.09$ & $58.43 \pm 5.49$ & $* *$ & $57.36 \pm 6.32$ & $59.35 \pm 5.21$ & $*$ & $55.66 \pm 5.62$ & $58.51 \pm 5.97$ & $*$ \\
\hline AH-OP(mm) & $38.13 \pm 3.99$ & $40.15 \pm 4.90$ & $* *$ & $39.70 \pm 5.76$ & $40.32 \pm 5.26$ & NS & $38.68 \pm 5.04$ & $40.09 \pm 5.11$ & NS \\
\hline AH-MP(mm) & $11.72 \pm 3.81$ & $12.26 \pm 4.53$ & NS & $12.89 \pm 3.98$ & $13.09 \pm 3.83$ & NS & $11.34 \pm 3.15$ & $12.64 \pm 3.57$ & NS \\
\hline AH-PNS(mm) & $55.62 \pm 3.92$ & $59.03 \pm 5.43$ & $* *$ & $58.12 \pm 6.31$ & $60.06 \pm 5.50$ & $*$ & $57.33 \pm 4.30$ & $60.12 \pm 5.02$ & $*$ \\
\hline $\mathrm{AH}-\mathrm{Y}(\mathrm{mm})$ & $34.72 \pm 4.68$ & $35.62 \pm 4.87$ & NS & $35.98 \pm 5.20$ & $36.25 \pm 5.05$ & NS & $35.06 \pm 5.05$ & $36.97 \pm 5.41$ & NS \\
\hline \multicolumn{10}{|c|}{ The horizontal measurements of tongue } \\
\hline AH-Or(mm) & $48.73 \pm 5.39$ & $49.19 \pm 6.34$ & NS & $50.56 \pm 6.95$ & $50.75 \pm 7.03$ & NS & $50.10 \pm 4.38$ & $51.15 \pm 5.22$ & NS \\
\hline $\mathrm{AH}-\mathrm{C} 3(\mathrm{~mm})$ & $30.68 \pm 2.44$ & $32.04 \pm 3.21$ & $*$ & $32.61 \pm 3.78$ & $33.62 \pm 3.72$ & NS & $1.71 \pm 3.40$ & $32.56 \pm 3.18$ & NS \\
\hline $\mathrm{AH}-\mathrm{RGn}(\mathrm{mm})$ & $32.79 \pm 4.74$ & $33.38 \pm 5.31$ & NS & $34.15 \pm 5.32$ & $34.53 \pm 5.23$ & NS & $33.74 \pm 5.39$ & $34.20 \pm 5.94$ & NS \\
\hline $\mathrm{AH}-\mathrm{Me}(\mathrm{mm})$ & $37.74 \pm 5.10$ & $38.48 \pm 5.36$ & NS & $38.74 \pm 6.03$ & $39.20 \pm 6.05$ & NS & $37.51 \pm 5.53$ & $38.49 \pm 5.21$ & NS \\
\hline $\mathrm{AH}-\mathrm{NPog}(\mathrm{mm})$ & $78.32 \pm 5.68$ & $83.69 \pm 6.74$ & $* *$ & $81.50 \pm 7.96$ & $85.04 \pm 8.60$ & $* *$ & $80.17 \pm 6.76$ & $82.74 \pm 6.77$ & $*$ \\
\hline $\mathrm{AH}-\mathrm{CVP}(\mathrm{mm})$ & $30.16 \pm 2.36$ & $31.52 \pm 2.96$ & $*$ & $31.94 \pm 3.72$ & $32.89 \pm 3.61$ & $*$ & $30.66 \pm 3.43$ & $32.02 \pm 3.70$ & $*$ \\
\hline
\end{tabular}

NS indicates statistical nonsignificance; * $\mathrm{P}<0.05 ; * * \mathrm{P}<0.01$

of soft tissue had also been remodeled. In Group A and B, Zangle increased significantly, this met the beautiful people criteria. The distance between Ls to E line decreased, and the position of Us changes from anterior to posterior of $\mathrm{E}$ line, which indicated that the facial appearance of the patients tended to be more harmonious. In addition, how much changes of the upper and lower lips could cause by the incisor position movement was also effected by the shape, thickness, tension, and other factors.

The changes of Overjet and Upper lip were significant, when comparing changes before and after treatment between Group A and $\mathrm{B}$. The reasons were as follows: the use of headgear in Group A; the overjet and inclination of maxillary and incisors of patients in Group A were more serious. So the changes were obvious in Group A than Group B.

In the upper airway-related variation, V-LPW, PNS-V, PNS-U, T$\mathrm{V}$ increased significantly in Group A and B after treatment. The result demonstrated that the changes were caused by Class II elastic traction rather than headgear.

Many studies ${ }^{18,19)}$ have shown that the oropharyngeal dimension is closely related to size and position of the mandible. $\mathrm{Abu}^{20)}$ found that the sagittal dimension of oropharynx was larger Class II malocclusion than that of Class II malocclusion. Maybe the further research is to assess the differences among various malocclusions in air way by different appliances.

Sahoo ${ }^{7)}$ researched the air way of dimensional changes and position of hyoid bone in adults with skeletal class II malocclusion treated by combined orthodontics and bilateral sagittal split ramus osteotomy in the method of lateral cephalograms. But more and more scholars suggested non-surgical treatment before or during puberty, which could decrease the severity of malocclusion. So we chose the people aged from 11-14 years in our study.

In the vertical and horizontal position of the hyoid bone variation, changes were similar in the three groups. The relative measurements increased, which indicated the direction of hyoid growth had been changed to forward and downward. Many scholars ${ }^{21,22)}$ confirmed that hyoid position gradually moved forward and downward from the mixed dentition to permanent dentition. Yassaei ${ }^{22}$ found that hyoid bone shifted significantly forward in horizontal dimension and no significantly upward in vertical dimension in the patients with Class II division I 
malocclusion treated with Farmand functional appliance. Because of the different treatment, the changes in vertical position were different. In this study, the changes of hyoid position may be related with Class II traction, as well as body growth.

Many researchers studies the air way and position of hyoid bone by cephalograms, rather than three-dimensional approach $^{21,22)}$. Cephalograms could be a good method of reflecting the changes, if the standard of taking and measuring the lateral cephalograms was well performed.

In conclusion, the upper airway dimensions could not be decreased by headgear treatment or Class II traction in patients with Class II division 1 malocclusion. Class II traction treatment affected the position of hyoid bone.

\section{Acknowledgement}

This research was supported partly by Liaoning Province Science and Technology Project (2013225090) from China.

\section{References}

1. Verma SL, Sharma VP, Singh GP and Sachan K. Comparative assessment of soft-tissue changes in Class II Division 1 patients following extraction and non-extraction treatment. Dent Res J 10:764-771, 2013

2. Yi Liu, Fan Liu, Ying Zheng and Xin Yu. Morphological characteristics of the cranial base in sagittal malocclusion. J Hard Tissue Biol 22: 249-254, 2013

3. Ferro F, Monsurro A and Perillo L. Sagittal and vertical changes after treatment of Class II Division 1 malocclusion according to the Cetlin method. Am J Orthod Dentofacial Orthop 118:150-158, 2000

4. Lima KJ, Henriques JF, Janson G, Pereira SC, Neves LS and Cançado RH. Dentoskeletal changes induced by the Jasper jumper and the activator-headgear combination appliances followed by fixed orthodontic treatment. Am J Orthod Dentofacial Orthop 143: 684-694, 2013

5. Na An, Yi Liu, Yan Wang, Lu Bai, Ying Zheng and Xin Yu. Morphological character of the cranial base in different vertical facial types. J Hard Tissue Biol 23: 323-327, 2013

6. Lopatiene $\mathrm{K}$ and Babarskas A. Malocclusion and upper airway obstruction. Medicina (Kaunas) 38: 277-283, 2002

7. Sahoo NK, Jayan B, Ramakrishna N, Chopra SS and Kochar G. Evaluation of upper airway dimensional changes and hyoid position following mandibular advancement in patients with skeletal class II malocclusion. J Craniofac Surg 23: e623-627, 2012

8. Ozdemir F, Ulkur F and Nalbantgil D. Effects of fixed functional therapy on tongue and hyoid positions and posterior airway. Angle Orthod 84: 260-264, 2014

9. Hiyama S, Ono T, Ishiwata $\mathrm{Y}$ and Kuroda $\mathrm{T}$. Changes in mandibular position and upper airway dimension by wearing cervical headgear during sleep. Am J Orthod Dentofac Orthop 120: 160-168, 2001

10. Lai EH, Yao CC, Chang JZ, Chen I and Chen YJ. Threedimensional dental model analysis of treatment outcomes for protrusive maxillary dentition: Comparison of headgear, miniscrew, and miniplate skeletal anchorage Am J Orthod Dentofac Orthop 134: 636-645, 2008

11. Yan L, Bin Y and Lin W. Two-phase treatment of skeletal Class II malocclusion with the combination of the Twinblock appliance and high-pull headgear. Am J Orthod Dentofac Orthop 142: 246-255, 2012

12. Kocadereli L. Changes in soft tissue profile after orthodontic treatment with and without extractions. Am J Orthod Dentofac Orthop 122: 67-69, 2002

13. Tulloch JFC, Proffit WR and Phillips C. Influences on the outcome of early treatment for Class II malocclusion. Am J Orthod Dentofac Orthop 111: 533-542, 1997

14. Jacobson A. Application of the "Wits" appraisal. Am J Orthod70: 179-189, 1976

15. Thomas ES, Steven DM and Veerasathpurush AL. An evidence-based comparison of headgear and functional appliance therapy for the correction of Class II malocclusions. Semin Orthod 19: 174-195, 2013

16. Sayin MO and Turkkahraman H. Comparison of dental arch and alveolar widths of patients with Class II division 1 malocclusion and subjects with Class II ideal occlusion. Angle Orthod 74: 356-360, 2004

17. Nimri AL. Changes in mandibular incisor position in Class II Division 1 malocclusion treated with premolar extractions. Am J Orthod Dentofacial Orthop 124: 708-713, 2003

18. Mahony D, Karsten A and Linder-Aronson S. Effects of adenoidectomy and changed mode of breathing on incisor and molar dentoalveolar heights and anterior face heights. Aust Orthod J 20: 93-98, 2004

19. Sheng CM, Lin LH, Su Y and Tsai HH. Developmental changes in pharyngeal airway depth and hyoid bone position from childhood to young adulthood. Angle Orthod 79: 484490, 2009

20. Abu Allhaija ES and Al-Khateeb SN. Uvulo-glossopharyngeal dimensions in different anterioposterior skeletal patterns. Angle Orthod 75: 1012-1018, 2005

21. Yu X, Fujimoto K, Urushibata K, Matsuzawa Y and Kubo $\mathrm{K}$. Cephalometric analysis in obese and nonobese patients with obstructive sleep apnea syndrome. Ches 124: 212-218, 2003

22. Yassaei S and Sorush M. Changes in hyoid position following treatment of Class II division1 malocclusions with a functional appliance. J Clin Pediatr Dent 33: 81-84, 2008 